\title{
A review paper on Actual properties of Epoxy Reinforced with Surface Modified Sisal Fiber
}

Dhananjay Yadav ${ }^{1}$, G. R. Selokar ${ }^{2}$

1 Department of Mechanical Engineering, Sri SatyaSai University of Technology and Medical Science, Sehore-46601, India

2 Department of Mechanical Engineering, Sri SatyaSai University of Technology and Medical Science, Sehore-46601, India

\section{ABSTRACT}

Recently, natural fibers attract the scientific community towards it usage as reinforcement in polymeric composites mainly because of environmental awareness, growing concern and multiple benefits like low cost, huge/easy availability, easy processing. Reinforcing natural fibers is an efficient approach towards reducing the consumption of nonbiodegradable plastic material. Though, the major drawbacks of such composites are poor compatibility between the two distinct phases and high rate of water absorption. It has been observed that with this drawback, degradation of different mechanical and thermal properties generally occurs. Keeping this in mind, in present work, the surface of the sisal fibers are modified with aqueous solution of $\mathrm{NaOH}$ at different concentration prior to reinforce it in epoxy matrix. Later, water absorption rate of the developed material is evaluated over a period of one week where measurement is taken after every 24 hours. Results obtained indicate that with surface modified sisal fiber, water absorption rate decreases appreciably. Further, it is also determined that rate of water absorption is minimum with 2 Mole $\mathrm{NaOH}$ concentrations. Also, the density is measured and evaluated theoretically to know the void content in the fabricated samples

\section{Key words:Physical Characterization, Mechanical Characterization , Tribology.}

\section{INTRODUCTION}

Composite, in actual is not a human invention. Wood is a natural composite material consisting of one species of cellulose fibers with good strength and stiffness reinforced in a resinous matrix of another polymer, the polysaccharide lignin. Generally, composites are defined as material which has combination of two or more distinct constituents. Following the above definition, a huge number of materials will come in this category which includes mud bricks with straw used in early age for building construction to modern man-made composite. In recent time, the composite prepared by human being captured a huge market where structure fabrication with low weight in combination with high strength and stiffness is of concerned.

\section{Classification of Composites Materials}

Classification of composites can be made in two different categories, first on the basis of matrix materials, in which it can be metal matrix composites, ceramic matrix composites and 
polymer matrix composites. It is observed that polymer matrix is further categorized as thermoset composites and thermoplastics composites. The same is explained as follows:Metal matrix composites generating a wide interest in research fraternity mainly because of their strength, fracture toughness and stiffness. Added advantage is that it can withstand elevated temperature even in corrosive environment. It has been seen that almost all metals and their alloys can be a matrix material. For forming a composite body, metal require a reinforcement material which will be stable over a wide range of temperature. Reinforcement also should not react with metal matrix. Generally, for temperature application, light metal were selected as matrix material and the reinforcement is added to provide high modulus.

\section{Function and properties of matrix}

Matrix used in preparation of composite has to fulfil different functions, and maximum of them are vital to the performance of the material. Only reinforcement without matrix is actually of no use for an engineer as the presence of continuous phase uplift the usage of it. The role of matrix is different and depends upon the type of reinforcement is added.

1. The main function of the matrix is to bind the fibers together and holding them in such a way that they will be aligned in the particular direction for which it is designed. It is the reason why load transferred to the fiber from composite.

2. The other important function of matrix is to isolate the fibers from one another. With this the main aim is to make fiber behave as separate entities.

3. Another very important function of matrix is to protect the reinforcing material from mechanical damage when load is applied over it. Matrix also protects the reinforcement material from ever changing environmental conditions.

4. When the matrix is ductile, it helps in slowing down the cracks produced due to breakage of fibers when they are within matrix body.

5. Toughness of the material depends upon the grip of matrix on reinforcement material. Better grip provide increased toughness.

6. Lateral support is provided by matrix against the compressive loading situation where the possibility of buckling of fiber present. In this way, matrix also helps in improving the overall compressive strength of the material.

\section{Function and properties of reinforcement}

Reinforcement plays important role in composite as it govern the fulfillment of requirement. According to the application for which composite is being designed, selection of proper reinforcement is done. Generally, fibers as reinforcement in composite uplift the mechanical properties of the composites, whereas filler as reinforcement improves the intrinsic properties of the composites.

1. To provide strength to material. Matrix has generally low in strength and reinforcement is used to enhance the strength property of the material.

2. Reinforcement generally makes the material stiffer.

3. It improves the directional properties of the composites.

4. Used in different size can improve packaging density of the material which can improve the overall properties of the material.

5. According to the requirement, intrinsic property of the material can be changed by incorporating proper reinforcing material.

\section{Objectives of present investigation}

On the basis of exhaustive literature review, the specific objectives of the present work are outlined as: 
1. Fabrication of series of epoxy based polymer composites reinforced with short sisal fiber by hand lay-up/compression molding techniques.

2. Surface modification of sisal fiber by proper chemical treatment to enhance the compatibility between the two phases.

3. To study the physical and mechanical properties of epoxy/short sisal fiber composites such as density, water absorption rate, tensile strength, compressive strength, flexural strength and hardness.

4. To characterize the two bodies abrasive wear behavior of such composites and study the surface morphology of the abraded composites using scanning electron microscopy.

5. Optimization and prediction of the effect of control factors on the abrasive wear behavior of composites using Taguchi experimental design.

\section{LITERATURE REVIEW}

A review of available literature is done to put forward the background information on the issues to be considered in this thesis and to highlight the importance of the present study. The review is focused on the various aspects of the natural fiber polymer composites with a special emphasis to sisal fiber reinforced polymer composites. This chapter contains review of existing research reports

- On natural fiber sources, types and properties

- On modification of natural fibers

- On physical and mechanical behavior of natural fiber reinforced polymer composites

- On wear behavior of natural fiber reinforced polymer composites

- On sisal fiber reinforced polymer composites

- On Implementation of Design of Experiments for wear analysis

Mwaikambo and Ansell [1] studied the effect of alkaline treatment of different plant fibers which include, hemp fiber, jute fiber, sisal fiber and kapok fibers. In their study, they observe that alkaline treatment results better compatibility between fiber and matrix and it is valid for all fibers. With increase in adhesion between fiber and matrix, interfacial energy increases and this further increases the mechanical and thermal properties of the developed material. Asumani et al. [2] performed alkaline treatment on kenaf fiber and reinforced it in polypropylene matrix. They compared the mechanical properties of composite with and without fiber treated composite and found significant improvement in mechanical properties when treated fiber were used. Similar observation is registered by

Reddy et al. [3] where they used Napier grass as reinforcement. In more recent work,

Saravanakumaar et al. [4] treated Carica papaya fibers with 5 wt. $\%$ of $\mathrm{NaOH}$ aqueous solution at room temperature. They varied the treatment time from 15 minutes to 90 minutes. They evaluated the mechanical properties of the fiber for different sets of composite fabricated on the basis of treatment time and reported that 60 minutes is the optimum time duration for the treatment of papaya fiber on the basis of result obtained.

Li et al. [5] studied the work performed by the various researcher on peroxide treatment compiled the work and concluded that peroxide is an effective treatment method when combine with alkaline treatment and increases the adhesive property which in turn improves mechanical properties. Also lot of work has been reported in which thermal stability are found to increase of the developed material. 
Sreekala et al. [6] applied peroxide treatment over oil palm fiber and fabricated a composite with thermoplastic matrix phenol formaldehyde. They compared the result obtained for untreated and treated fiber and found appreciable increase in mechanical properties when treated fiber is used.

Dolez et al. [7] worked on the steric acid treatment of jute fiber. They used a combination of steric acid and ethanol for completing the process of surface modification. They evaluated the efficiency of the treatment in two different terms like water contact angle and retention time of water drop shape. They further evaluated the water absorption rate and found appreciable decrement in that post treatment.

Madsen and Lilholt [8] evaluated the density of unidirectional composite with polypropylene as matrix body with flax fiber reinforced in it. The density was evaluated with the help of Archimedes principle. In their casecase, the density of polypropylene is less as compared to the density of flax fiber and hence density of composite increases with the content of fiber. The increment is limited because fiber density is low and is very much close to that of the density of matrix.

joseph et al. [9] on which they evaluated the dependency of voids formation on the cooling rate of short sisal fiber reinforced polypropylene composites and found that with increase in rate of cooling voids generation increases whereas with low cooling rate, crystalline growth restricted. Hence, in there study they optimize the rate of cooling. The prime interest of studying voids in composite is to quantify the effect of voids in mechanical properties of polymeric composites.

Wismon et al. [10] studied the effect of voids on inter laminar shear strength of the fiber reinforced polymer composites. They have studied the effect of length of voids on inter laminar shear strength rather than content of voids. They reported that when length of voids increases from $0.28 \mathrm{~mm}$ to $3.00 \mathrm{~mm}$, ILSS decreases by $23 \%$ and the decrement is proportional to the length. The decrement is with respect to the material without voids content.

Van Den Broucke et al. [11] studied the effect of void content on the tensile properties of woven fiber composites. They reported that with increase in $1 \%$ of void content in composites, tensile properties decreases by around $6 \%$. In other study,

Kakakasery et al. [12] established dependency of residual flexural strength of composites with void content. They reported that the residual strength is slightly higher for a highvoidage laminate because large voids enhance the resistance to delamination, which is the predominant failure mode in post-impact flexural loading.

Azwa and Yousif [13] treated kenaf fibers with aqueous solution of $\mathrm{NaOH}$ and reported to achieve around $3 \%$ reduction in water absorption rate as compared to raw kenaf fiber reinforced composite.

Jumaidin 3t al. [14] studied water absorption behavior of sugar palm fiber reinforced thermoplastic composites and found that with increase in the content of fiber, water absorption rate increases.

Hom et al. [15] used non-woven hemp fiber as reinforcement material in polyester resin and found that increase in fiber content increases the void content as well water intake rate of the composites.

Jannah et al. [16] used banana fiber as reinforcing material in polyester resin. They used different chemical treatment methods to improve the adhesion between fiber and matrix and 
to induce hydrophobic behavior in banana fiber. Among the various treatment method, they observed maximum reduction in moisture absorption rate with acrylic acid.

Sanjay et al. [17] suggested that hybridization natural fiber with synthetic fibers enhances the resistance towards water absorption. They used combination of jute and kenaf fiber with Eglass fiber and observed that water absorption rate reduces significantly.

\section{MATERIAL AND METHODS}

\section{Raw material used}

In present work, short fiber reinforced polymer composites are fabricated. The polymer used is a thermoset polymer named epoxy resin and the fiber used is sisal fiber which is a natural fiber.

\section{Epoxy}

Matrix materials are the base of composite fabrication. The presently used matrix is a thermoset polymer epoxy. The epoxy resin Lapox-12 is used in the present work which belongs to the epoxide family.

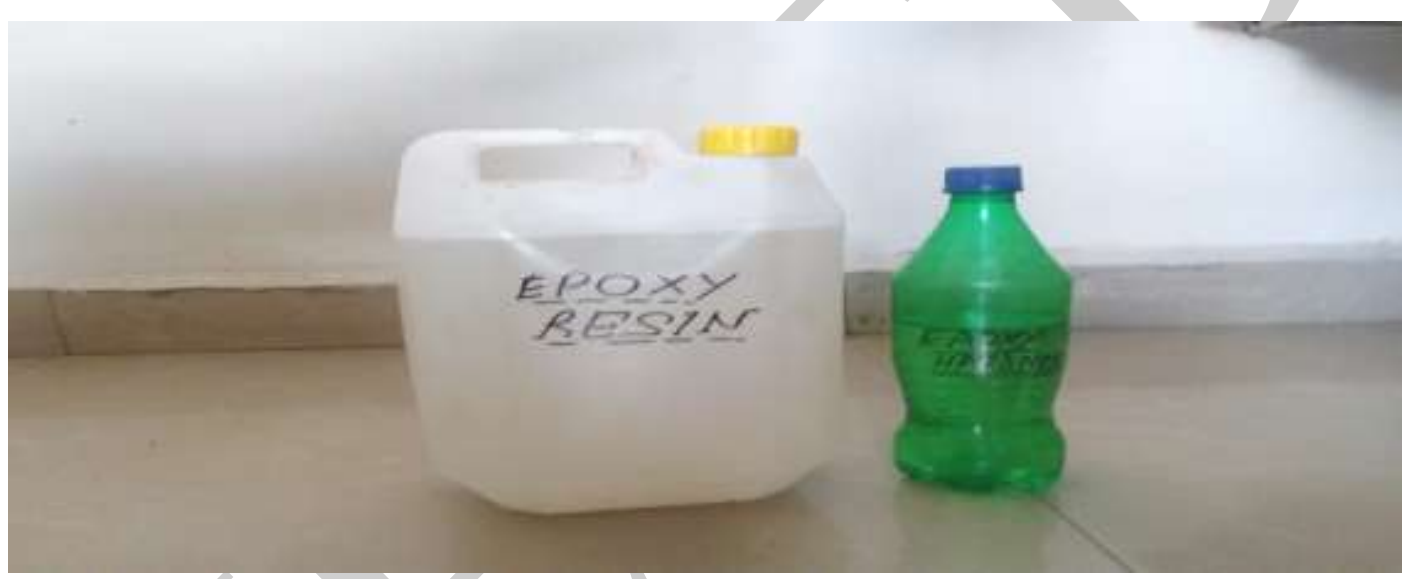

\section{Sisal Fiber}

Figure 1 Chain of tri-ethylene-tetramine

The Sisal fiber used in present work was obtained from the local market as it is used in rural areas for making cord, met etc. The fiber was extracted from the leaf of the plant AgaveSisalana which is available in plenty in the Southern part of India.

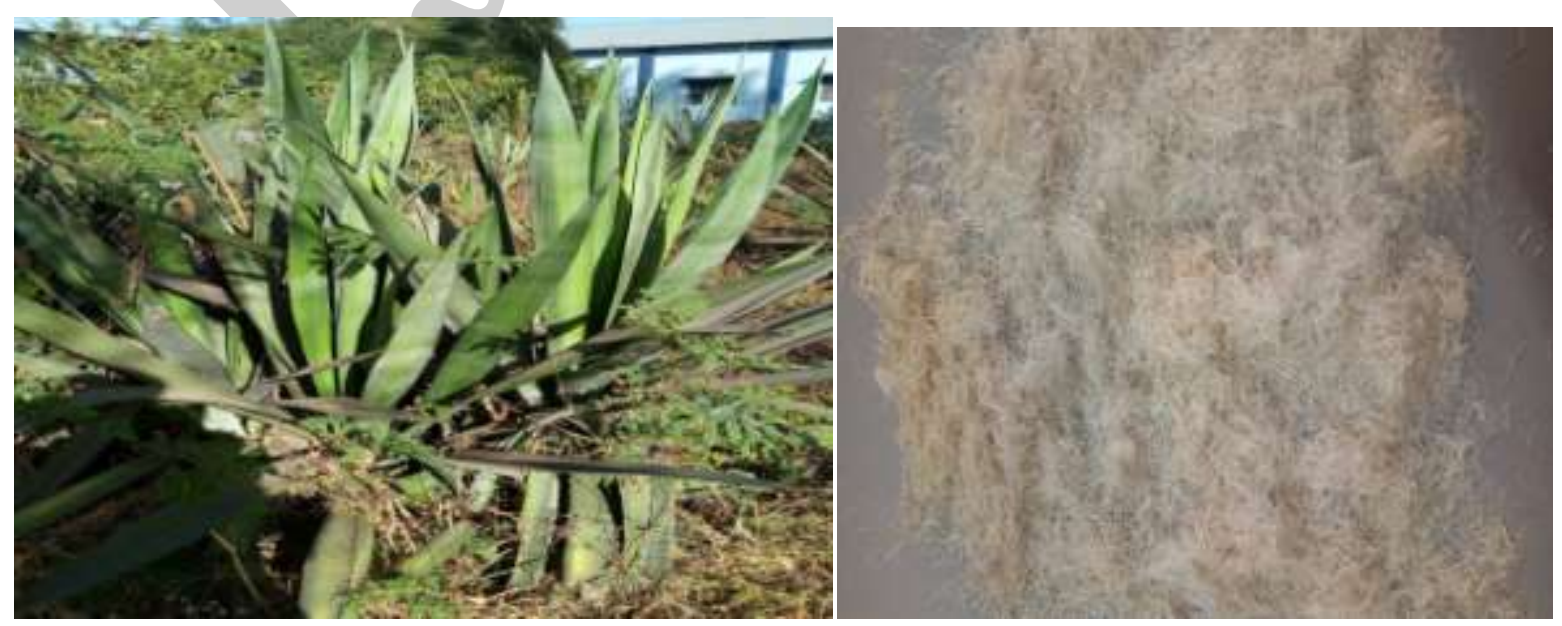

Figure 2 Long and short sisal fiber 


\section{Density Measurement and void fraction}

The experimental density $\left(\rho_{c e}\right)$ of composites under study is determined by using Archimedes principle using distilled water as a medium (ASTM D 792-91). The relationships between the mass of the body, the volume of the body and the density of solid body immersed in liquid as described by Archimedes form a basis for the determination of the density of substances. According to the principle, if density of the liquid is known and the volume of the liquid displaced is measured,

\section{Water absorption rate}

Water absorption rate of the composites is investigated as per ASTM D 570. The specimens were submerged in water in room temperature for study the kinetics of water absorption. The samples were taken out periodically i.e. after each 24 hours and weighted immediately. The content of water absorption by sample was found out using a precise weighing machine. The test duration is not fixed at it is depended upon the time span in which the saturation level reach i.e. further intake of water by composites ceases.

\section{Mechanical Characterization}

Evaluating mechanical behavior of any developed material is required to prove the feasibility of the material. Mechanical characterization of the samples includes tensile strength, flexural strength, compressive strength and hardness. Tensile, compressive and flexural tests under consideration are conducted in computerized Instron 3382 Universal testing machine. The pictorial view of universal testing machine used for present investigation

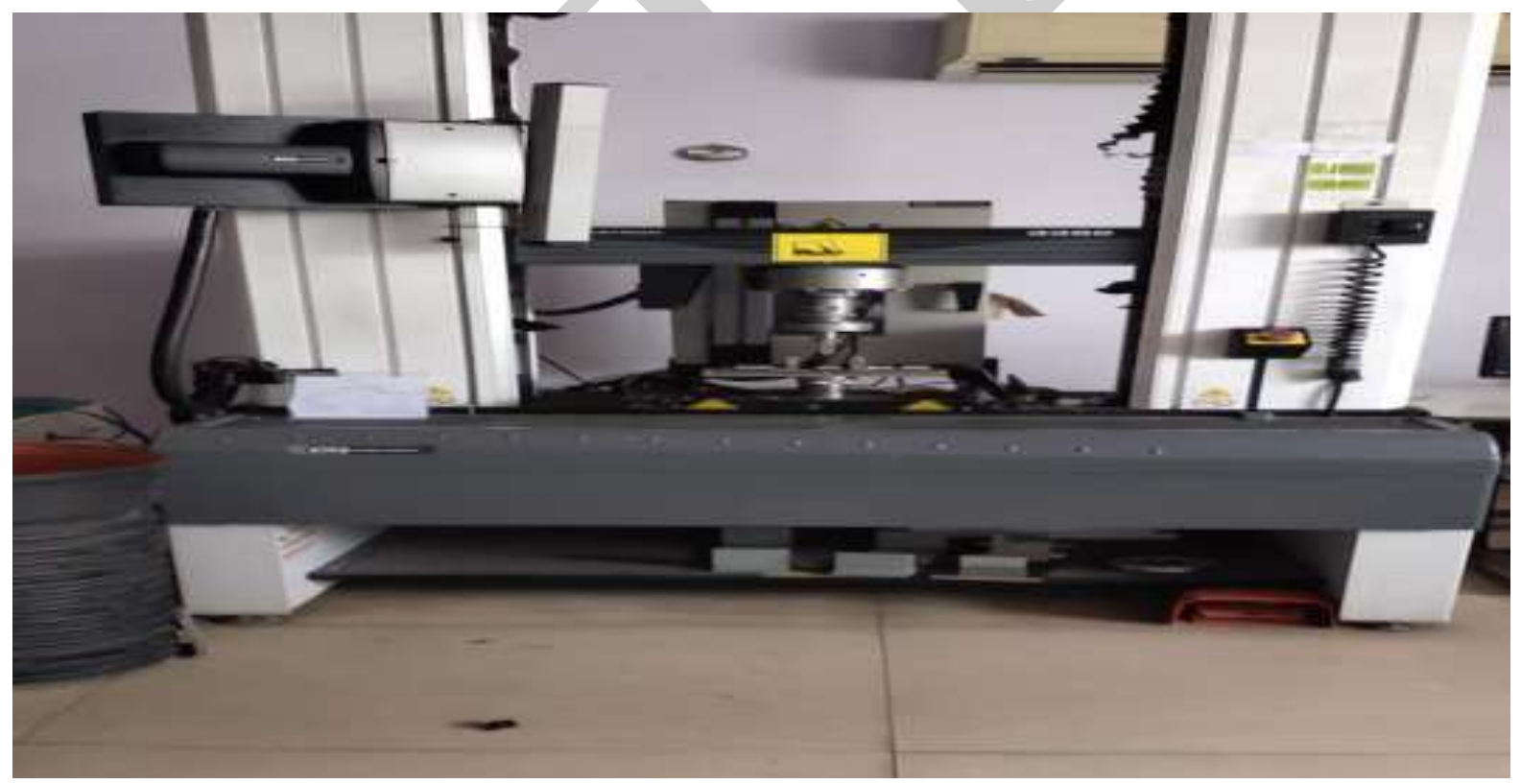

Figure 3Instron 3382 universal testing machine

\section{CONCLUSION}

Various mechanical properties like tensile strength, flexural strength, impact strength etc. Of a natural composite depend on various factors like: (a) Type of fiber (b) Volume Fractional of Fiber (c) Fiber Loading. Fibers are more significant effect on mechanical properties of natural composites. Outcome from Literature Survey reported that the For the short fiber reinforced polymer composite as the aspect ratio increase fatigue strength also increase and having the higher tensile strength. Results of glass, banana fiber and epoxy resin having higher tensile 
strength, flexural strength compare to jute polyester composite and also having good automotive application.

\section{REFERENCE}

1. Mwaikambo, L. Y., \& Ansell, M. P. (2002). Chemical modification of hemp, sisal, jute, and kapok fibers by alkalization. Journal of applied polymer science, 84(12), 2222-2234.

2. Asumani, O. M. L., Reid, R. G., \&Paskaramoorthy, R. (2012). The effects of alkali-silane treatment on the tensile and flexural properties of short fibre non-woven kenaf reinforced polypropylene composites. Composites Part A: Applied Science and Manufacturing, 43(9), 1431-1440.

3. Reddy, K. O., Maheswari, C. U., Shukla, M., \&Rajulu, A. V. (2012). Chemical composition and structural characterization of Napier grass fibers. Materials letters, 67(1), 35-38.

4. Saravanakumaar, A., Senthilkumar, A., Saravanakumar, S. S., Sanjay, M. R., \& Khan, A. (2018). Impact of alkali treatment on physico-chemical, thermal, structural and tensile properties of Carica papaya bark fibers. International Journal of Polymer Analysis and Characterization, 23(6), 529-536.

5. Li, X., Tabil, L. G., \&Panigrahi, S. (2007). Chemical treatments of natural fiber for use in natural fiber-reinforced composites: a review. Journal of Polymers and the Environment, 15(1), 25-33.

6. Sreekala, M. S., Kumaran, M. G., Joseph, S., Jacob, M., \& Thomas, S. (2000). Oil palm fibre reinforced phenol formaldehyde composites: influence of fibre surface modifications on the mechanical performance. Applied Composite Materials, 7(5-6), 295-329.

7. Zafeiropoulos, N. E., Williams, D. R., Baillie, C. A., \& Matthews, F. L. (2002). Engineering and characterisation of the interface in flax fibre/polypropylene composite materials. Part I. Development and investigation of surface treatments. Composites Part A: Applied Science and Manufacturing, 33(8), 1083-1093.

8. Dolez, P. I., Arfaoui, M. A., Dubé, M., \& David, É. (2017). Hydrophobic treatments for natural fibers based on metal oxide nanoparticles and fatty acids. Procedia engineering, 200, 81-88.

9. Joseph, P. V., Joseph, K., Thomas, S., Pillai, C. K. S., Prasad, V. S., Groeninckx, G., \&Sarkissova, M. (2003). The thermal and crystallisation studies of short sisal fibre reinforced polypropylene composites. Composites Part A: Applied Science and Manufacturing, 34(3), 253-266.

10. Wisnom, M. R., Reynolds, T., \&Gwilliam, N. (1996). Reduction in interlaminar shear strength by discrete and distributed voids. Composites Science and Technology, 56(1), 93101.

11. Van Den Broucke, B., Hegemann, J., Das, R., Oster, R., Hackl, K., \&Stößel, R. (2007). Modelling of textile reinforced composites using finite element tools and investigation of the influence of porosity on mechanical properties. Finite element modelling of textiles and textile composites, 26-28.

12. Kakakasery, J., Arumugam, V., Rauf, K. A., Bull, D., Chambers, A. R., Scarponi, C., \&Santulli, C. (2015). Cure cycle effect on impact resistance under elevated temperatures in carbon prepreg laminates investigated using acoustic emission. Composites Part B: Engineering, 75, 298-306.

13. Azwa, Z. N., \&Yousif, B. F. (2013). Characteristics of kenaffibre/epoxy composites subjected to thermal degradation. Polymer degradation and stability, 98(12), 2752-2759.

14. Jumaidin, R., Sapuan, S. M., Jawaid, M., Ishak, M. R., \&Sahari, J. (2016). Characteristics of thermoplastic sugar palm Starch/Agar blend: Thermal, tensile, and physical properties. International journal of biological macromolecules, 89, 575-581. 
15. Dhakal, H. N., Sarasini, F., Santulli, C., Tirillò, J., Zhang, Z., \&Arumugam, V. (2015). Effect of basalt fibrehybridisation on post-impact mechanical behaviour of hemp fibre reinforced composites. Composites Part A: Applied Science and Manufacturing, 75, 5467.

16. Jannah, M., Mariatti, M., Abu Bakar, A., \& Abdul Khalil, H. P. S. (2009). Effect of chemical surface modifications on the properties of woven banana-reinforced unsaturated polyester composites. Journal of Reinforced Plastics and Composites, 28(12), 1519-1532.

17. MR, S., \&Yogesha, B. (2016). Study on water absorption behaviour of jute and kenaf fabric reinforced epoxy composites: hybridization effect of e-glass fabric. International Journal of Composite Materials, 6(2), 55-62.

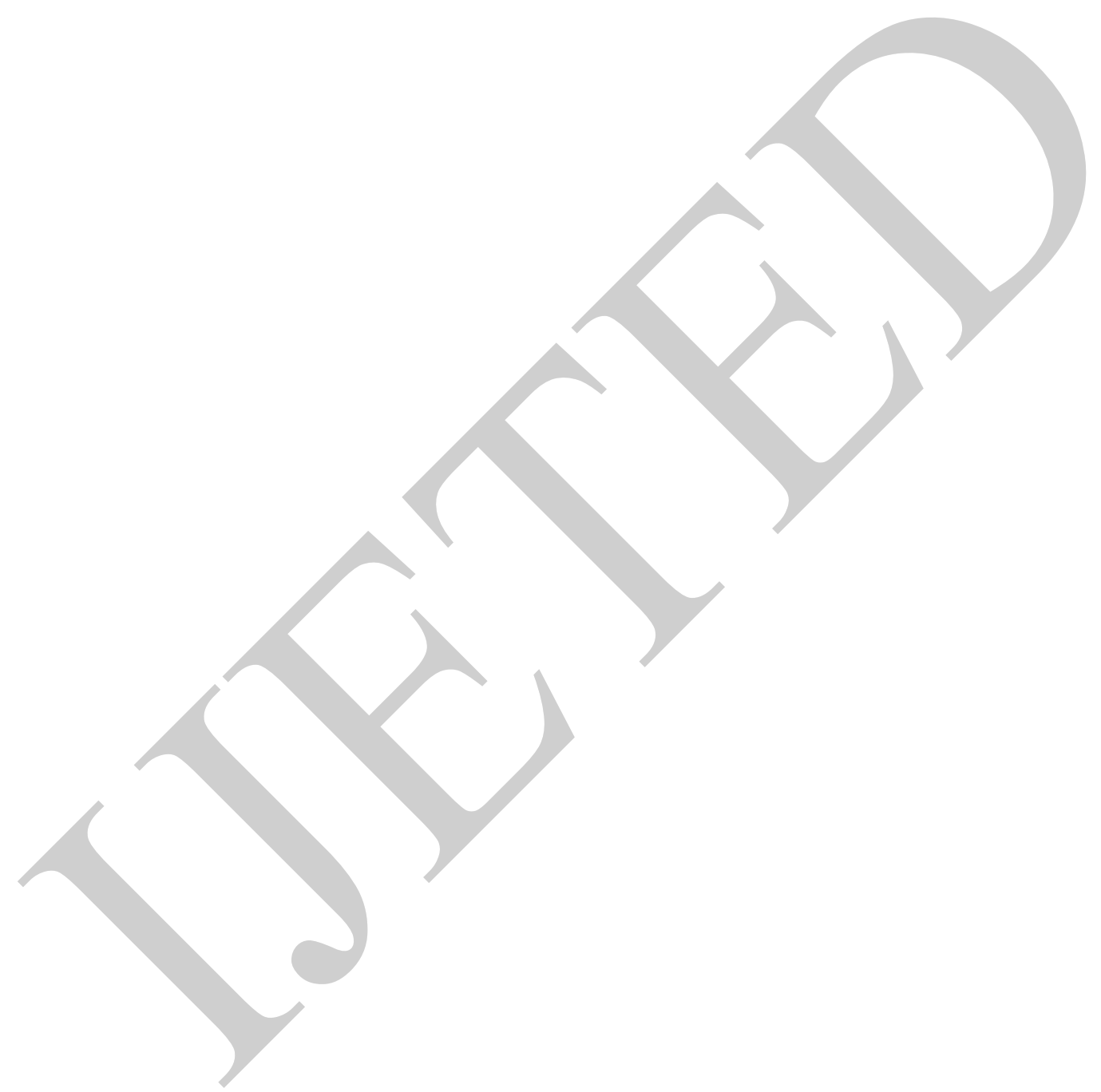

